THURSDAY, SEPTEMBER II, I873

\section{THE ENDOWMENT OF RESEARCH}

$\mathrm{VI}$.

A MONG the difficulties which are likely to impede the ready realisation of the object to which attention has been drawn, there remains one which will always bc most keenly felt by those who have devoted the most thought to the question. Beneath the word "Science" there lurks a distressing ambiguity, which, though it may not force itself upon the attention of the devoted students of any particular branch, is always arising when the general claims of scientific study come on for discussion. For our present purpose it is particularly important to attach that meaning to the word which, while best justified by usage, is also most calculated to conciliate good will from all quarters.

It will hardly be denied that the name primarily belongs to those sciences called by way of distinction "natural," in the name of which this journal is con. ducted, and which therefore it is needless to enumerate here; and that the name is thence transferred, by reason of analogies of varying degrees of strength, to those other branches of knowledge which either in their logical methods or positive results approximate to the standard of the physical sciences. Although it would be presumptuous to attempt to lay down with exactness the line which must somewhere exist between scientific and unscientific knowledge, it must yet be always necessary to treat with much suspicion the claims of mere erudition and of social theorising to be admitted to the honoured name. The old-fashioned reputation of the grammarian or the divine, and the modern popularity of practical reformers, are neither of them grounds on which to found a title to national endowment. The unprofitable studies for which the Universities were once famous have for centuries been abundantly rewarded, and the applause of a crowded congress is ever ready to acknowledge the merits of a novel speculation in Sociolozy. It is not unnatural that those who know by hard experience what Science really is should jealously uphold the dignity of their pursuits, and point with pride to the, innumerable advantages which mankind within the last century has reaped from their labours: but, on the other hand, the warning is not unneeded at the present day that the field of the physical sciences is not equal in extent to that which all scientific knowledge can comprehend, and that the appeal to utility may be turned into a fallacious argument. Yet further, it may be urged that those among the sciences which most attract the public attention at the hands of an accomplished experimentalist, and of which the direct practical applications are manifest to all, are least in immediate want of support from national endowments. It is for the languishing departments of Science, which have not been popularised, and of which the results have not yet been turned to commercial value, that the advantages of en. dowment are most required. As soon as ever the main principle of these articles is publicly recognised, the more advanced and most useful are certain to obtain sufficient care, but it is for the more backward and the least profitable that the need of help is most urgent.

No, 202-Vor. virr.
It may be reasonably expected that the Universities, as their traditions become modified under the influence of the public demands, will be disposed to accept the duty of endowing scientific research under the limitations above indicated. They can have no antecedent prejudice in favour of those branches of science which either attract the most spectators, or the greatest number of self-interested students. They have always refrained with anxiety both from bidding for popularity, and from preparing their pupils for the technical business of life. Their historic position also, and the peculiar responsibilities which they cannot but feel, will cause them to interpret Science in a liberal fashion. For thesc reasons it is confidently hoped that, while they cannot afford to disregard the paramount importance of the physical sciences, they will maintain the position to which other sciences more closely connected with their present curriculum have of late years grown. The former, on account of their rigorous methods, the positive character of their results, and the abundance of their possible applications must always hold the first place, and present a standard for the rest; but these others also, in so far as they are really matters of scientific treatment, are in their proper sub. ordination equally fields for original research and proper objects for endowments. The example of the German Universities has familiarised our own seats of learning with the notion that the study of languages, of antiquities, and of history, are all capable of being pursued in the genuine scientific spirit, and may lead directly to the most important positive results. Abundant evidence has been given within the last few years to show that the primitive condition of mankind and the origin of civilisation are matters which may be revealed by Science. The metaphysical explanations of the last century have given way before the well-ordered facts and regular uniformities which modern inquirers have been able to discover and arrange. The products of the human mind, and the course of human action, when displayed in their simplest and most universal forms, have been proved to be proper subject-matter for Science, no less than the law of man's physical organism or the processes of external nature. The most advanced thinkers have no hesitation in saying that the origin of natural religion is capable of being disclosed by the same methods and with equal certainty as the origin of species, and that philology yields an instrument which can unfold the secrets of an unknown past as surely as the spectroscope reveals the composition of unknown worlds. Just as modern psychology has found it necessary to borrow a large portion of its materials from the kindred science of comparative physiology, so have the nascent sciences alluded to above been under a continual obligation to the methods of physical science, and especially those to which they are linked by means of the recognised science of ethnology.

By thus widely extending the meaning of the word Science, the intention has been to widen the arez over which the endowments of original research may be extended, and to give an indication of the number of directions in which scientific investigation should beencouraged. As an indirect consequence it may be suggested that this aspect of the matter shows an easy method by which the don of the last generation, an acute critic mercly in longs and shorts, and erudite only in Greek particles, may be 
changed, without any violent transformation, into the modern scientific student. It is not so much that the subject-matter of his studies will be different, for in this respect the reform must be gradual, and is already being carried out, but that the whole spirit of his pursuit must be altered along with the tenure of his office. The principle throughout advocated is not that money should be abstracted from the Universities for general scientific objects, but that the large funds which they cannot need for the purposes of teaching, should, for the future, be devoted, not as prizes to their successful examinees, but for the support of those engaged in original scientific work : and it is contended that this is the sole means by which they can justify their retention at all of this surplus, and by which also the main objects of the first givers can be carried out. It must also be noticed that this development of our scheme brings out into greater clearness the old position that the obligation of teaching would be merely an incumbrance on our new scientific fellow. Discoveries in Science, especially those of the most important kind, are made in such a tentative fashion, and are proved by such elaborate inferences, as to be quite incapable of being communicated orally to a class; nor indeed would it be desirable that researches, as soon as made, should be forthwith promulgated from the professor's chair. The growth of Science, whether physical or not, must in many cases be militant, and may be left much more profitably to the student, who is ever investigating with a single eye to the truth, than to the teacher, who must be always careful of the form in which his doctrine is to be conveyed.

We trust, therefore, that by this attempt to show that the meaning of scientific research is not so restricted as it has been some times represented; not only has the general thesis of these articles been strengthened, but also that new adherents may be conciliated in favour of a cause which promises to connect together the followers of physical science and those at the Universities who alone worthily maintain the dignity of their ancient studies; and it must always be understood that we have looked upon the Universities as representing local State action, and that the nation must do universally what we think should be done by the University authorities locally at Oxford and Cambridge.

c.

\section{EUROPEAN SPIDERS}

Remarks on Synonyms of Europcan Spiders. By T. Thorell, Ph.D., Junior Professor of Zoology in the University of Upsala. (Upsala, 1870-73, pp. 1-6.44.) EW branches, perhaps, of entomological science
show the effects of independent and?isolated labours more strikingly than Arachnology-limiting this term here to the order Araneidea (or Aranex). The great works of N. UVestring on Swedish Spiders, published in r86r, that of Mr. Blackwall on those of Great Britain and Ireland, published I86I-64, and the "Catalogue Synonymique des Araneides d'Europe," by M. Eugène Simon (included in his general work " Histoire Naturelle des Araignées," published I864), are an instance representing very strongly the fruits of this isolated labour in the same branch of natural history science. These authors appear to have been, and indeed, it is believed, actually were-the two former at all events-totally igno. rant of each other's existence. M. Simon, indeed, quotes Mr. Blackwall occasionally in his "Catalogue Synonymique," but his knowledge of that author's works was apparently confined to the scanty and often erroneous quotations in Baron Walckenäers' "Insectes Aptéres." Mr. Blackwall then and MI. Westring, each in his own way and with the works of other authors more or less at their common command, plodded on for years in parallel paths. Both worked diligently and laboriously, at, for a very great part, as a glance at the map would suggest, identical objects; their labours at length resulting in the respective volumes above mentioned. So much as this however can hardly be said in regard to the third one of the works noted. The "Catalogue Synonymique" bears few marks of labour at the objects themselves which it enumerates, and is in fact a mere desk work, remarkable chiefly for the limited and often infelicitous use of the materials undoubtedly available at that epoch to any author professing to gather together and to harmonise the independent and scattered morsels of an extensive branch of natural science. The good work, however, done since, and being now daily done in Arachnology by M. Simon, will soon obliterate the remembrance of the comparative failure of the more ambitious efforts of his early years.

Towards these isolated works of Mr. Blackwall and Mr. Westring the minds of Arachnologists in more than one quarter appear soon to have been directed, with a view to bring their parallel lines together. Dr. T. Thorell - of the University of Upsala-a countryman and personal friend fof Mr. Westring, and an accomplished scholar, was the first to move publicly in it : and bringing great ability and $d_{1}$ clearness of head to bear upon the subject, designed an almost exhaustive work on "European Spiders." Of this work, and under that title, was published in 1869-70, Part I. with the special title of "Review of the European Genera of Spiders, preceded by some Observations on Zoological Nomenclature." This portion of the proposed work appeared in the "Nova Acta Regix Societatis Scientiarum Upsaliensi5," ser. iii. vol. vii. Fasc. i. et ii.; but owing to some unforescen difficulty, and unfortunately for the external continuity of the two portions of the work, the second part, intended to treat upon the more special division of the subject, was published in $1870-73$ as a separate work in a different form and with an independent title, being that given at the head of this notice, viz. "Remarks on Synonyms of European Spiders;" this is, however, as may be at once seen from the respective introductions to the two, although the title of the second does not allude to it, really Part II. of the originally designed work, "On European Spiders." It is thus evident that though the present notice is upon the second work, it could not be adequately considered without first remarking briefly upon the one which preceded.

Dr. Thorell's stated object ("European Spiders," p. I) being to fix the nomenclature of the spiders described in the works of Blackwall and Westring, it was obviously necessary first to decide upon the genera recognised by them, and by those authors also to whom they refer; and for both this and the subsequent determination of the specific name to which each spider was entitled, it was, 